\title{
Percepções do consumo do pequi em Palmas (TO): entre o contentamento e a indiferença
}

Perceptions of pequi consumption in Palmas (TO): between contentment and indifference

Las percepciones del consumo de pequi en Palmas (TO): entre la alegría y la indiferencia

http://dx.doi.org/10.18472/cvt.17n1.2017.1077

Stella Maria Carvalho de Melo <stella@ifpi.edu.br >

Instituto Federal do Piauí (IFPI), Teresina, PI, Brasil.

Eveline Porto Sales Aguiar < evelineporto@ifce.edu.br > Instituto Federal do Ceará (IFCE), Aracati, CE, Brasil.

Geruza Aline Erig 〈geruza@ifto.edu.br > Instituto Federal do Tocantins (IFTO), Palmas, TO, Brasil.

CRONOLOGIA DO PROCESSO EDITORIAL

Recebimento do artigo: 05-ago-2015

Aceite: $23-j a n-2017$

FORMATO PARA CITAÇÃO DESTE ARTIGO

MELO, S. M. C. de; AGUIAR, E. P. S.; ERIG, G. A. Percepções do Consumo do Pequi em Palmas (TO): entre o contentamento e a indiferença. Caderno Virtual de Turismo. Rio de Janeiro, v. 17, n. 1, p. 73-87, abr. 2017.

$$
\text { REALIZAÇÃO }
$$

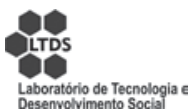

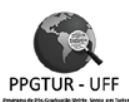

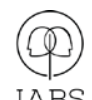

APOIO INSTITUCIONAL

EDIÇÃO

PATROCÍNIO

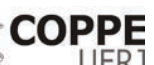

UFR]

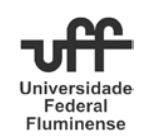

IPBS

.

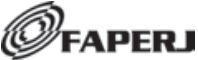




\section{RESUMO}

Os turistas, ao chegarem à capital do Tocantins, têm contato com a culinária local, que é uma mistura das culinárias indígena, mineira, goiana e nordestina, com forte presença de frutos do cerrado, como pequi, utilizado em diversas receitas doces e salgadas. Esse contato fortalece aspectos fundamentais da cultura local. Assim, o presente artigo buscou analisar de que forma a gastronomia e a cultura estão interligadas, por meio do consumo do pequi na cidade de Palmas, tanto por turistas como por moradores. Para tanto, sua metodologia consistiu em uma pesquisa descritiva quantitativa, com levantamento de campo. Foram entrevistados 300 consumidores em 34 estabelecimentos de alimentos e bebidas, nos meses de março e abril de 2015. Como resultado da pesquisa, verificou-se que o pequi é muito apreciado pela comunidade local da capital, sendo um tipo de alimento bem aceito pela maioria de sua população. Já para os turistas que não têm o hábito cultural de consumir tal iguaria, verificou-se que há uma certa resistência ao seu consumo. Desse modo, o consumo do pequi divide-se entre a sua apreciação e a sua aversão.

Palavras-chave: Comida típica. Consumo. Gastronomia. Pequi. Palmas, TO.

\section{ABSTRACT}

When tourists arrive at the capital of Tocantins, they have contact with the local cuisine, which is a mixture of Mineira, Goiana, Native, and Northeastern cuisines, with a strong presence of fruits of cerrado, such as pequi. Pequi is used in many salty and sweet recipes. This contact enhances fundamental aspects of the local cultures. Thus, this paper aims to examine how the gastronomy and culture are interconnected through pequi consumption in the city of Palmas, either by tourists as well as by locals. In order to achieve this goal, the methodology employed consisted of a quantitative descriptive research with field survey. 300 consumers were interviewed in 34 different stores of food and beverages, in the months of March and April, 2015. As a result of the research, it was found that the pequi is much appreciated by the local community of the capital, being a type of food well accepted by most of its population. As for tourists who do not have the cultural habit of consuming this delicacy, it was found that there is some resistance to its intake. Thus, pequi consumption ranges from appreciation to disgust.

Keywords: Typical food. Consumption. Gastronomy. Pequi. Palmas, TO.

\section{RESUMEN}

Los turistas que llegan a la capital de Tocantins tienen contacto con la cocina local, que es una mezcla de la cocina de los indios, del estado de Minas Gerais y Goiás y de la región noreste, con una fuerte presencia de las frutas del cerrado, como el pequi, que se utiliza en varias recetas, dulces y saladas. Ese contacto refuerza los aspectos claves de la cultura local. Así, este trabajo tiene como objetivo examinar cómo la gastronomía y la cultura están interconectadas a través del consumo de pequi en la ciudad de Palmas, tanto por los turistas como por nativos. Por lo tanto, la metodología consistió en una investigación descriptiva cuantitativa con estudio de campo. Entrevistamos a 300 consumidores en 34 tiendas de alimentos y bebidas en los meses de marzo y abril de 2015. Como resultado de la investigación, se encontró que el pequi es muy apreciado por la comunidad local de la capital, es un tipo de alimento bien aceptado por la mayoría de su población. En cuanto a los turistas que no tienen el hábito cultural de consumo de ese manjar, se identificó que hay alguna resistencia a su uso. Así pues, el consumo de pequi se divide entre su apreciación y su repugnancia.

Palavras clave: Comida típica. Consumo. Gastronomía. Pequi. Palmas, TO. 


\title{
Introdução
}

Em todo o mundo, milhares de pessoas se deslocam para os mais variados lugares, pelos mais variados motivos, entre eles a busca por lazer, entretenimento, negócios, eventos, cultura e gastronomia. A prática do turismo envolve conhecer não só aspectos tangíveis, como praias, montanhas, museus e parques, mas também aspectos intangíveis das localidades, como desfrutar e conhecer sobre a cultura e a gastronomia local.

Qualquer turista, ao visitar uma cidade, tem contato direto com a culinária local, seja por interesse direto ou indireto, já que esta é uma necessidade elementar. Os números do "turismo gastronômico" no mundo ainda não são claros, mas a crescente procura por destinos que têm forte relação com a gastronomia chama atenção.

A gastronomia tem uma intrínseca ligação com a cultura, e está tendo maior destaque como um produto do segmento de turismo cultural. Para Reinaldo Dias (2006, p. 39),

\begin{abstract}
o turismo cultural é uma segmentação do mercado turístico que incorpora uma variedade de formas culturais, em que se incluem museus, galerias, eventos culturais, festivais, festas, arquitetura, sítios históricos, apresentações artísticas e outras, que, identificadas com uma cultura em particular, fazem parte de um conjunto que identifica uma comunidade e que atraem os visitantes interessados em conhecer características singulares de outros povos.
\end{abstract}

Com o tempo, surgiram novas motivações de viagens, entre elas a busca pelo prazer através da alimentação. Conforme Schlüter (2003, p. 11),

\begin{abstract}
a cozinha tradicional está sendo reconhecida cada vez mais como um componente valioso do patrimônio intangível dos povos. Ainda que o prato esteja à vista, sua forma de preparação e o significado para cada sociedade constituem os aspectos que não se veem, mas que lhe dão seu caráter diferenciado.
\end{abstract}

Desse modo, o estudo sobre comidas típicas de uma região turística pode contribuir para o resgate de antigas tradições, além de fortalecer aspectos fundamentais da cultura local. Isso vem acontecendo na cidade de Palmas, TO, a última capital a ser criada no Brasil e portal de entrada para o Parque Estadual do Jalapão, uma Unidade de Conservação, com território total de 53,3 mil km², formado pelos estados da Bahia, Piauí, Maranhão e Tocantins, que atrai milhares de turistas a cada ano em busca da prática do ecoturismo em dunas, cachoeiras, trilhas e fervedouros (piscinas naturais), segundo Dutra (2016).

O roteiro Palmas-Jalapão foi considerado por $47 \%$ dos turistas pesquisados pelo Serviço de Apoio às Micro e Pequenas Empresas (Sebrae), em 2009, como bom ou excelente, necessitando apenas maior divulgação das cidades e seus atrativos, e diversificação do produto Jalapão (ADTUR, 2011).

Palmas recebe, prioritariamente, turistas das regiões Centro-Oeste e Norte do país, que se destinam à região do Jalapão, além de turistas de negócios e eventos. Porém, a capital também possui atrativos naturais como: o Lago de Palmas, formado pelo represamento do Rio Tocantins e utilizado para banho, pesca, esportes náuticos, esportes de praia e passeios de barco; Praia do Caju, Praia da Graciosa, Praia do Prata e Praia dos Arnos, praias fluviais utilizadas como balneário pelos moradores locais; cachoeiras situadas em distritos próximos, entre outros (ADTUR, 2011).

Ao chegarem à capital, esses turistas têm contato com a culinária local, que é uma mistura das culinárias indígena, mineira, goiana e nordestina, com uma forte presença de frutos do cerrado, como cagaita, araticum, baru, buriti e pequi. 
O cerrado ocupa cerca de $25 \%$ do território nacional e sua flora é caracterizada pela presença de espécies espaças, com galhos retorcidos, onde convivem gramíneas e espécies lenhosas, semelhante a uma formação de savana. Essa formação é rica em espécies nativas frutíferas, com interesse na alimentação.

Entre os frutos típicos desse ecossistema, destaca-se o pequi, considerado a "carne" do cerrado, reunindo proteínas, carboidratos e um alto teor de vitaminas A e C, conforme Oliveira e Rocha (2008), e amplamente utilizado em diversas receitas doces e salgadas, nos restaurantes e bares locais.

Assim, o presente artigo buscou analisar de que forma a gastronomia e a cultura estão interligadas por meio do consumo do pequi na cidade de Palmas, TO, tanto por turistas como por moradores.

\section{Metodologia}

A metodologia deste trabalho consistiu em uma pesquisa descritiva quantitativa, com levantamento de campo. Segundo Dencker (1998, p. 151), "a pesquisa descritiva, em geral, procura descrever fenômenos ou estabelecer relações entre as variáveis. Utiliza técnicas padronizadas de coletas de dados, como questionário e a observação sistemática". Ainda conforme a autora, "os levantamentos de campo têm por objetivo a geração de dados estatísticos, procurando resultados que permitam a generalização dos resultados" (DENCKER, 1998, p. 158).

Para a delimitação do universo desta pesquisa, utilizaram-se os dados do último inventário turístico realizado no estado pela Agência de Desenvolvimento Turístico do Tocantins (ADTUR, 2011). Segundo esse inventário, foram identificados em Palmas 110 estabelecimentos gastronômicos. Destes, 42 são restaurantes/bares que oferecem serviço à la carte, por quilo ou ambos, o que corresponde a $38 \%$ do total. O restante, 68 estabelecimentos, são lanchonetes, fast-food, snack-bar, pizzarias, cafés, padarias e outros.

Definiu-se como foco deste trabalho apenas os 42 restaurantes/bares que oferecem serviço à la carte, por quilo ou ambos, pois nesses estabelecimentos é mais provável encontrar pratos que contenham o pequi, além de serem locais mais frequentados por turistas. Esses restaurantes oferecem pratos regionais, comidas contemporâneas e internacionais, atendendo a públicos variados em diversos pontos da cidade e em locais próximos a hotéis e pousadas.

Destes, 20 oferecem apenas o serviço à la carte (48\% dos restaurantes/bares), 12 oferecem apenas o serviço de buffet ou por quilo (28\%) e 10 oferecem ambos os serviços (24\%).

Para a delimitação da amostra, utilizou-se o programa Raosoft (2015), com nível de confiança de 80\% e margem de erro de 5\%. Assim, chegou-se ao número de 34 restaurantes/bares a serem pesquisados.

A escolha dos estabelecimentos pesquisados foi feita de modo aleatório e com base nos locais onde seus gerentes se disponibilizaram a responder ao questionário. Desse modo, foram pesquisados 16 restaurantes à la carte, dez restaurantes a quilo ou buffet e oito que oferecem ambos os serviços.

Quanto ao número de consumidores pesquisados, foi utilizada uma amostragem não probabilística por conveniência, aquela onde o pesquisador seleciona o que acredita ser a melhor amostra para seu estudo, pois o universo de frequentadores dos restaurantes/bares era desconhecido. Esse tipo de amostragem é aquele em que "a possibilidade de escolher determinado elemento do universo é desconhecida", segundo Dencker (1998, p. 214). 
Desse modo, foram pesquisados aproximadamente oito consumidores por restaurante, aleatoriamente, em cada restaurante/bar selecionado, totalizando 300 consumidores. Destes, 283 eram moradores de Palmas e 17 eram turistas.

A pesquisa foi realizada no período de 6 de março a 24 de abril de 2015, e procurou-se conhecer a origem desses consumidores e se eles gostam ou não de comer pequi, nas suas mais variadas formas, além de identificar quais estabelecimentos ofereciam pequi no seu cardápio e em quais pratos.

\section{Gastronomia e cultura}

A alimentação humana é um ato social e cultural, onde a escolha dos alimentos é definida por um conjunto de fatores econômicos, históricos, culturais, ecológicos e sociais, ligado a uma rede de representações, simbolismos e rituais, segundo Alvarez (2002). Assim, a necessidade da alimentação converge para a necessidade que o ser humano detém para que possa sobreviver e ser capaz de realizar as suas atividades básicas do dia a dia.

De tal modo, pode-se afirmar que o homem ao longo da sua história de vida trava uma luta contra a fome e precisa saciá-la em definidas horas, para que não padeça de fome. O conceito de fome perpassa a saciedade ao se refletir que "não é apenas a sensação universal que todos possuímos antes de comer, mais bem chamada de apetite, mas o estado crônico de carências nutricionais que podem levar à morte por inanição ou às doenças da desnutrição" (CARNEIRO, 2003, p. 24).

Assim, Schlüter (2003, p. 13) chama atenção da alimentação como uma fonte de sustento e de nutrição, uma vez que "a alimentação cumpre com uma função biológica ao fornecer ao corpo as substâncias indispensáveis para sua subsistência". Ou seja, o alimento está vinculado intrinsecamente ao ato da alimentação, como uma necessidade fisiológica do homem.

Dessa maneira, o ato de se alimentar resulta na saciedade das necessidades fisiológicas do ser humano, bem como proporciona a convivência entre os comensais e os prazeres à mesa. Assim, convém mencionar que junto ao ato de se alimentar e da consequência dos desejos e necessidades superados, há que se refletir na arte de cozinhar, que nasceu juntamente com o homem pré-histórico. Quando este descobriu o fogo, simultaneamente desenvolveu armas para caçar animais, fisgando e prendendo a presa, sem ter a necessidade de sair para caçar novamente, o que, consequentemente, levou esses homens a fixar acampamento por mais tempo (LEAL, 2007).

Desse modo, esses homens são parte fundamental na formação da arte da cozinha, considerados pelo esforço empregado para sobreviver e buscando o alimento na sua particularidade mais simples que se podia ter para saciar a sua fome. Logo, o homem foi desenvolvendo seu cérebro e formatou utensílios de cerâmica com a finalidade de armazenamento, conservação e cocção dos alimentos. Emergiu, assim, a culinária propriamente dita, com suas ervas e sementes aromáticas para acentuar o sabor dos alimentos (LEAL, 2007).

Portanto, meditando-se nas palavras cozinha e culinária, ambas são palavras sinônimas, reportandose ao conjunto de utensílios, ingredientes e pratos típicos de um país ou de uma região. Por conseguinte, cozinha e culinária significam a arte de preparar os alimentos, por meio de métodos e técnicas direcionadas para esta finalidade (FREIXA; CHAVES, 2012). 
Assim, nesse estudo também se faz necessário refletir sobre o termo "gastronomia", que se trata de uma definição mais extensa, e sobre a cozinha contida em uma das partes da gastronomia, aludindo à cocção, ou seja, cozinhar. Por conseguinte, "a palavra culinária vem do latim culinarius, que deriva da palavra culina, significando cozinha. Diz respeito à arte de cozinhar e pode ser caracterizada por um conjunto de aromas e sabores peculiares a uma dada cultura" (GARCIA; CASTRO, 2011, p. 92).

Dessa maneira, Freixas e Chaves (2012, p. 20) acrescentam que "a gastronomia também está ligada às técnicas de cocção e ao preparo dos alimentos, ao serviço, às maneiras à mesa e ao ritual da refeição". Logo, a cozinha e a culinária estão inseridas na gastronomia, sendo o alimento e a cozinha precedentes à gastronomia.

Nessa reflexão, compreende-se a gastronomia como o somatório de história, cultura, arte e religião, por fazer parte de diferentes etapas da história do povo e do mundo. Falar em gastronomia é evidentemente pensar na história da humanidade, em que as receitas e as formas de preparo são reflexos da cultura.

Nas palavras de Reinhardt (2002, p. 8) "através do alimento podemos identificar uma sociedade, uma cultura, uma religião, um estilo de vida, uma classe social, um acontecimento ou uma época". Entende-se, portanto, a gastronomia não como apenas uma simples receita e o seu modo de preparo, mas como os valores históricos e culturais presentes nos pratos.

Segundo Castelli (2006, p. 271), "a refeição tem sido uma ocasião ímpar para a prática da sociabilidade e da convivência na longa caminhada do homem para chegar até a sociedade contemporânea”. Ademais, o prazer pela boa mesa retrata:

[...] o prazer que advém de várias circunstâncias, fatos, lugares, coisas e pessoas que acompanham a refeição. É prazer peculiar à espécie humana. Pressupõe cuidados com o preparo da refeição, com a arrumação do local onde será servida e com o número e tipo de convivas (FRANCO, 2001, p. 23).

Para Schlüter (2003, p. 30), "se considerarmos a alimentação como parte de uma cultura, as normas que a regem criam diferenças de ordem social e, inclusive, de gênero, estabelecendo-se uma diferença entre o elegante e o vulgar, o bom e o mau, o comestível e o não comestível". Ou seja, para cada cultura o ato de comer um determinado alimento tem um significado próprio.

A alimentação é, portanto, um elemento de diferenciação de culturas, onde cada identidade é construída. Do ponto de vista do turismo, a alimentação pode ser uma estratégia de desenvolvimento local (GIMENES, 2011), pois a partir do momento que uma comunidade começa a explorar um determinado tipo de comida típica, esse alimento passa a ser reconhecido e procurado pelos turistas, gerando renda e empregos para a comunidade local.

Dessa forma, o alimento deixa de ser consumido por suas características físico-químicas e passa a ser degustado pelos valores simbólicos que lhe são atribuídos, conforme Gimenes (2011). Isso acontece com o acarajé baiano, o churrasco gaúcho, o pão de queijo mineiro, entre outros alimentos que se tornaram símbolos de determinadas regiões turísticas. Ao degustar um prato típico, o turista ou morador conecta-se com a cultura local, tendo contato com sabores diversos, técnicas e ritos próprios da localidade.

Os pratos ou comidas realmente típicos têm essa propriedade, pois um acarajé feito em São Paulo - SP, por exemplo, jamais terá o mesmo sabor que um acarajé feito tradicionalmente pelas baianas em Salvador - BA, pois nele não estarão inclusos as características, sabores e modos de preparo originais dessa iguaria. 
Esses pratos típicos se destacam pela sua própria característica alimentar, pelas ressignificações e readaptações, assim como pelo empenho das comunidades em preservar e divulgar esses alimentos. Segundo Gimenes (2013, p. 32), os pratos típicos

\begin{abstract}
se ligam à história e ao contexto cultural de um determinado grupo, constituindo uma tradição que se torna símbolo de sua identidade. Os pratos típicos (ou comidas típicas) são entendidos, portanto, como integrantes da cozinha regional que emergem deste conjunto mais amplo por inúmeras razões (praticidade, associação a outra prática cultural, associação a determinadas celebrações) e passam a ser reproduzidos com finalidade simbólica e podem ser degustados como tal, desde que o comensal possua conteúdos capazes de permitir tal experiência.
\end{abstract}

Entre os mais variados alimentos da culinária de uma região, algumas iguarias se destacam mais que as outras, tornando-se dessa forma alimentos-signos. Para Gimenes (2013), alimento-signo é aquele que engloba uma série de significados e valorações simbólicas, cuja degustação transcenda a experiência sensorial e se caracterize também como uma experiência emocional e cultural.

Para especialmente degustar esses pratos, alguns turistas viajam para regiões turísticas, realizando, assim, o que chamamos de Turismo Gastronômico, que, segundo Gândara, Gimenes e Mascarenhas (2009, p. 181) é "uma vertente do turismo cultural no qual o deslocamento de visitantes se dá por motivos vinculados às práticas gastronômicas de uma determinada localidade".

A prática de se valorizar a identidade regional por meio da gastronomia é abordada por Poulain (2004, p. 38) da seguinte forma:

\begin{abstract}
a patrimonialização do alimentar e do gastronômico emerge num contexto de transformação das práticas alimentares vividas do modo de degradação em mais amplamente no de risco e perda da identidade. A história da alimentação mostrou que cada vez mais identidades locais são postas em perigo, a cozinha e as maneiras à mesa são os lugares privilegiados de resistência.
\end{abstract}

Portanto a gastronomia aparece como um bem comum do conjunto de qualquer comunidade que deseja preservar seus valores culturais, tornando-se um valor a ser cultivado. Segundo Lan et al. (2012), o turismo gastronômico pode ser considerado como uma viagem para um destino com propósitos culturais, unindo experiências únicas com alimentos que têm um apelo afetivo. Ainda conforme os autores, os viajantes normalmente têm o desejo por novos sabores, saberes e conceitos na destinação, e embora a maioria desses viajantes possa não escolher o seu destino apenas por razões alimentares, eles podem acabar lembrando da viagem pela comida que eles experimentaram no destino.

Ritchie et al. (2011) já afirmavam que a comida deve ser considerada um elemento vital de experiências de turismo, porque os turistas podem formar uma importante imagem de uma destinação, podendo influenciar na escolha do destino turístico ou na tomada de decisão. Por esse motivo, divulgar e explorar a gastronomia local como um produto turístico pode levar a vantagens competitivas no mercado turístico.

Porém, para degustar um prato típico não é necessário ser turista. Os moradores também devem e podem consumi-los, para que essa tradição seja valorizada e perpetuada para as gerações futuras.

É evidente que a relação entre a gastronomia e o turismo acontece decorrente das mais variadas formas para a sua realização, pois a necessidade de se alimentar é básica e indispensável, independentemente do tipo de atrativo e, ao mesmo tempo, a busca por novos sabores acaba favorecendo a atividade turística.

Na maioria das vezes, o turista vai a um restaurante com o objetivo de saciar a fome. Nesse momento, ele tem a oportunidade de saborear um alimento típico e também conhecer um pouco da cultura desse local por meio de sua gastronomia. A gastronomia é uma arte na qual quem a executa e quem a aprecia estão em perfeita sintonia, pois nela estão contidos o cotidiano e a história de quem a criou. 
O turismo surge como um dos elementos que utiliza a alimentação regional em suas atividades (FAGLIARI, 2005). O autor comenta ainda que a alimentação se mostra como um elemento fundamental na prática da atividade, tanto com relação à alimentação convencional, que tem por objetivo a nutrição do visitante, quanto pelo fato de oferecer produtos alimentares regionais como parte integrante do patrimônio cultural dos povos.

É importante, então, compreender como a gastronomia pode se tornar um importante atrativo cultural para o turismo, principalmente quando por meio dela o turista puder conhecer tradições e culturas diferentes da sua, remetendo à ideia de traços e expressões culturais onde ela acontece, lembrando sempre que a cultura propriamente dita é variada e dinâmica, e seus processos mudam de conteúdo e significado de um lugar para o outro.

\section{Pequi como alimento}

O pequi pode ser colhido facilmente em Palmas nos meses de setembro e outubro, e seu caroço (semente) é utilizado em pratos salgados, como arroz ou feijão com pequi, frango com pequi, risoto de pequi, pastel com pequi, torta de legumes com pequi, óleo de pequi, sanduíche de pequi, galinhada com pequi, e pratos doces, como torta de leite condensado com pequi, bombom de pequi, brigadeiro de pequi, mousse de pequi, biscoito de pequi, geleia de pequi, pequi in natura ou em conserva, e até em forma de licor.

Em Palmas, os pequizeiros brotam com facilidade em qualquer área que tenha espaço para o crescimento da árvore, já que o clima e o solo são propícios ao desenvolvimento desta. Nas áreas que ainda possuem vegetação nativa, é fácil encontrar pequizeiros abarrotados de frutos em meados do mês de setembro.

O fruto do cerrado está presente em todo o estado, sendo componente da alimentação de todas as classes sociais. Desde a ocupação colonial tornou-se alimento nobre e indispensável da culinária tocantinense cuja safra é esperada com ansiedade pela população a partir do mês de setembro.

Isso porque, como outras frutas do cerrado, entre elas o buriti, o pequi não tem uma produção constante ano após ano. Quando a árvore troca a folha verde-escura pela roupagem verde-clara no outono, é garantia de que a produção será boa. E se for boa, em meados do mês de julho estará florida, carregada de flores de filamentos e pétalas brancas. Essa florada atrai várias espécies de animais que procuram o pequizeiro para alimentar-se dessas flores. (BELUZZO, 2004).

Os consumidores sabem que a fruta estará apta para o consumo quando esta cai da árvore. Não se deve colher os grandes frutos no cacho, pois a maioria dos frutos colhidos dessa forma murcham. As feiras nas cidades tocantinenses, em outubro e novembro, pico da safra, exibem à venda os pequis colhidos no cerrado. Nas margens das rodovias são frequentes sacos e mais sacos cheios dos frutos à venda para os motoristas.

Hoje, apesar da proteção estabelecida em lei, o pequizeiro é extremamente ameaçado pelo avanço agropecuário e emprego na indústria do carvão vegetal. A árvore do pequizeiro é uma das maiores do cerrado, podendo atingir até $10 \mathrm{~m}$ de altura. Possui um tronco de casca áspera, rugosa e cinza escura, com raízes profundas e capacidade de desenvolvimento em solos rasos, pobre em nutrientes, minerais, e rico em teor de alumínio (DEUS, 2008). 
O fruto é do tamanho de uma pequena laranja e está maduro quando sua casca fica na cor verdeamarelada e amolece, revelando de uma a quatro amêndoas tenras envoltas por uma polpa amarela, branca ou rosácea (RODRIGUES, 2004).

O Pequi (Caryocar brasiliense Camb.) é uma espécie arbórea nativa dos cerrados brasileiros, pertencente à família Caryocaraceae, segundo Araújo (1995 apud SANTOS, 2005). É encontrado em alguns estados da região Norte, Centro-Oeste e Nordeste do Brasil, e sua nomenclatura varia conforme a região, podendo ser conhecido como piqui, piquiá-bravo, amêndoa-de-espinho ou grão-de-cavalo (SANTOS, 2005).

De acordo com Deus (2008), o pequizeiro é considerado uma espécie de grande interesse econômico, devido à ampla capacidade de utilização das partes da planta, como a casca, madeira, folhas, raiz, fruto e amêndoa, fatores responsáveis por esse interesse socio-econômico pelo pequi.

\section{Consumo do pequi em Palmas, To}

A gastronomia de Palmas revela em sua tipicidade regional e local o apreço pelo pequi, tendo a sua cozinha representada não como uma simples receita e o seu modo de preparo, mas com os valores históricos e culturais presentes nos pratos.

O consumo do pequi não é um consenso pelos moradores de Palmas. Isso se dá pelo fato de a população palmense ser bastante diversificada e mesclada de migrantes de outras regióes do país, que escolheram a capital do Tocantins para morar e trabalhar. Segundo Santos (1997, p. 160),

O gosto alimentar é determinado não apenas pelas contingências ambientais e econômicas, mas também pelas mentalidades, pelos ritos, pelo valor das mensagens que se trocam quando se consome um alimento em companhia, pelos valores éticos e religiosos, pela transmissão intergeração (de uma geração à outra) e intrageração (a transmissão vem de fora, passando pela cultura no que diz respeito às tradições e à reprodução de condutas), e pela psicologia individual e coletiva que acaba por influir na determinação de todos estes fatores.

Nesse sentido, a tendência pelo gosto de um determinado alimento vem de sua origem cultural, onde "integrantes de grupos sociais tendem a compartilhar certas aptidões de escolha (gosto) que terminam por conectá-los, tornando-os passíveis de serem reconhecidos como tal, inclusive no plano das decisões alimentares", conforme Gimenes (2013, p. 26).

Giard (1996) afirma, ainda, que as pessoas tendem a se identificar com hábitos alimentares de sua infância. Na pesquisa, constatou-se que 30\% dos pesquisados que afirmaram não gostar de pequi não são, originalmente, da região do cerrado (estados do Tocantins, Goiás, Maranhão, Piauí e Distrito Federal), ou seja, não tinham o contato com a fruta desde a sua infância, o que pode levar a não gostar da mesma na fase adulta.

Tais informações corroboram a afirmação de Ramos e Stein (2000): a infância é o período de formação dos hábitos alimentares. $\mathrm{O}$ entendimento dos fatores determinantes possibilita a elaboração de processos educativos, que são efetivos para mudanças no padrão alimentar das crianças. Tais mudanças irão contribuir no comportamento alimentar na vida adulta.

O comportamento alimentar é complexo, incluindo determinantes externos e internos ao sujeito. $\mathrm{O}$ acesso aos alimentos, na sociedade moderna, predominantemente urbana, é determinado pela estrutura socioeconômica, a qual envolve principalmente as políticas econômica, social, agrícola e agrária. Assim, 
as práticas alimentares, estabelecidas pela condição de classe social, engendram determinantes culturais e psicossociais (GARCIA, 2003).

Dos moradores de Palmas, 50\% já residem na capital do estado do Tocantins há mais de 10 anos, sendo bem adaptados aos costumes e tradições locais. Outros $24 \%$ vivem entre 5 a 9 anos, $14 \%$ entre 2 a 4 anos e os outros $12 \%$ estão há menos de 2 anos na cidade, mas já estão se adaptando aos costumes locais.

Palmas é uma cidade jovem, tem apenas 26 anos e está em desenvolvimento. Conhecida como a capital das oportunidades, a cidade recebe um grande fluxo de pessoas com intuito de melhorar de vida ou crescer profissionalmente. Um fato notório é que o fluxo imigratório é algo que faz parte tanto do seu passado como de seu presente.

A imigração e emigração atingiram substancialmente o Tocantins entre os anos de 1981 e 1991, período em que Palmas foi criada. O censo demográfico realizado pelo Instituto Brasileiro de Geografia e Estatística (IBGE), em 2010, demonstra que somente 24,54\% da população residente em Palmas era natural do município, $51,9 \%$ era de outros municípios tocantinenses e $48,10 \%$ de municípios de outros estados brasileiros, principalmente dos estados do Maranhão, Goiás e Pará (IBGE, 2010).

Das pessoas entrevistadas, $64 \%$ afirmaram que gostam do pequi, e apenas 36\% disseram que não gostam, conforme Figura 1. Dos que gostam, 21\% preferem consumi-lo apenas cozido, 36\% apenas com outros alimentos, como galinha, arroz ou feijão, e $43 \%$ consomem de ambas as formas. Mesmo se ele fosse consumido cru, ainda seria um consumo baseado pela característica cultural, já que a noção do que é comestível ou não é uma atribuição de cada cultura.

\section{Consumo do Pequi}

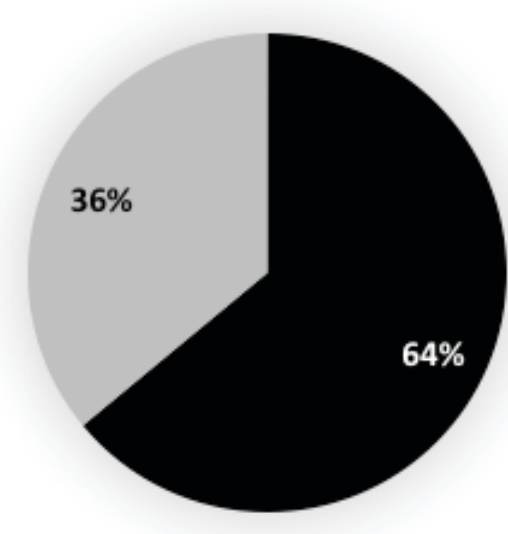

- Gostam Não gostam

Figura 1 - Consumo do Pequi

Fonte: Elaboração própria (2016). 
A história da evolução humana está diretamente ligada à alimentação. Entre todas as espécies existentes na natureza, o ser humano é a que possui a alimentação mais rica e variada. A descoberta dos processos de cozimento enriqueceu e ampliou o cardápio, permitindo o desenvolvimento de culinárias próprias e regionais. A necessidade biológica de alimentar-se para sobreviver e garantir a continuidade da espécie adquiriu então caráter cultural. Só o ser humano cultiva com requinte e abundância a grande variedade de pratos e sabores tão peculiares em cada parte do mundo.

Segundo Maciel e Menasche (2003), o hábito alimentar individual reflete uma série de valores da sociedade e, portanto, expressa a relação cultural e social que cada pessoa estabelece com o meio em que vive. A culinária, de fato, expressa a cultura de um povo de forma contundente. Analisando-a, é possível descobrir até mesmo o tipo de economia que move o país. Alguns hábitos são passados de geração a geração, outros vão sendo adaptados de acordo com as mudanças na sociedade.

A cultura sempre foi um elemento orientador das opções dietéticas. A abordagem cultural transforma a nutrição não somente em um processo químico-biológico, mas também em uma forma de comunicação que contém as raízes de cada povo, suas forças sagradas e seu simbolismo. A manutenção das práticas alimentares tradicionais e a gastronomia típica aproximam os seres humanos, inserindo-os no contexto de sua territorialidade e identidade cultural.

Das 110 pessoas que afirmaram não gostar de pequi, $44 \%$ reprovam esse alimento por conta do sabor, $34 \%$ por causa do cheiro forte, $10 \%$ nunca provaram, $7 \%$ reprovam por conta da consistência e o restante (5\%) por outros motivos, conforme Figura 2. Esses dados revelam que os principais motivos da reprovação do pequi são o sabor forte ou ruim e o cheiro forte ou desagradável que ele possui.

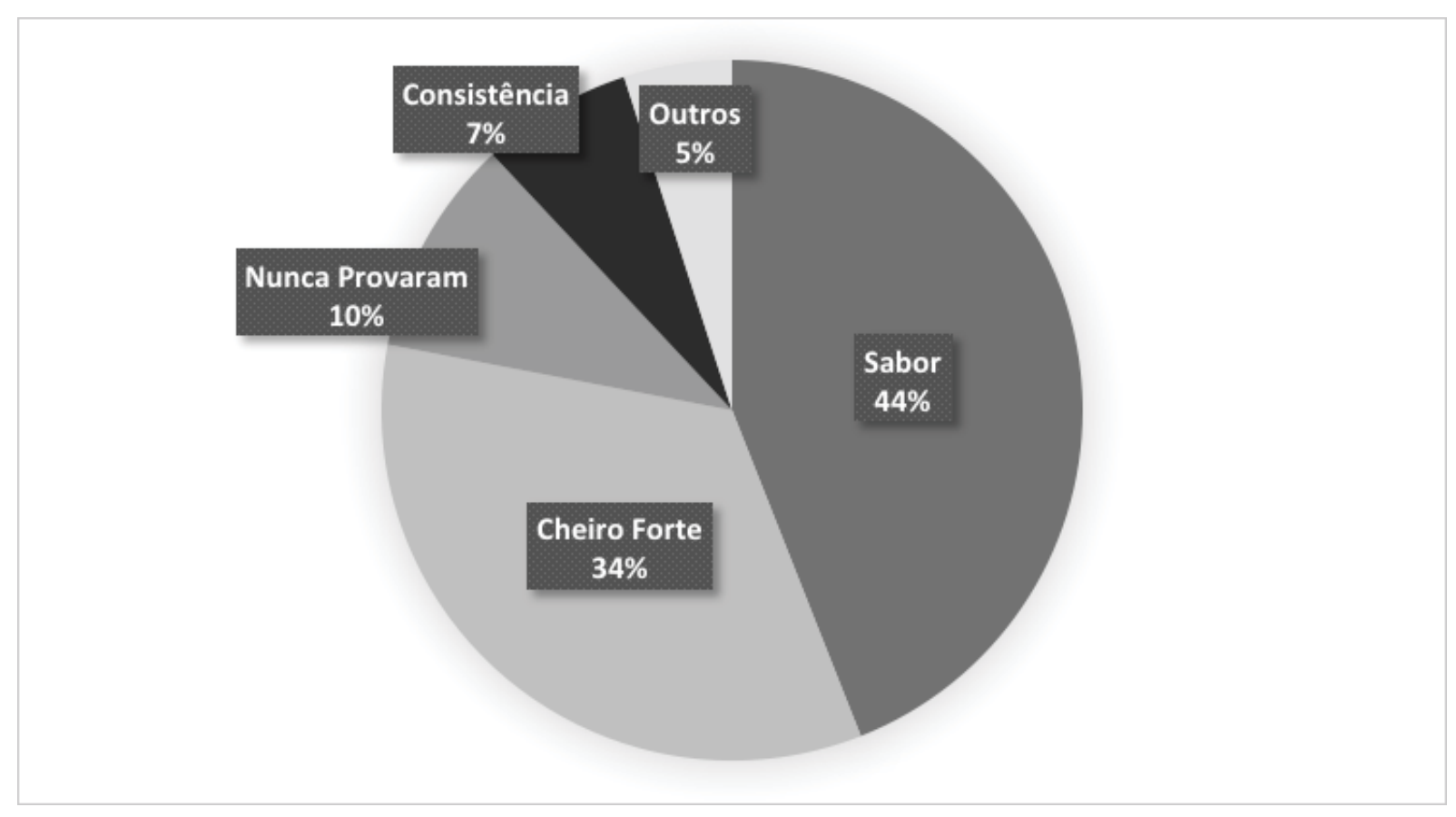

Figura 2 - Motivos de reprovação do pequi

Fonte: Elaboração própria (2016). 
Segundo Birch (1999), os fatores fisiológicos envolvidos com a formação do hábito alimentar são de diversos tipos. Entre eles estão incluídas as preferências pela doçura e pelo sabor salgado e a rejeição pelos sabores azedo e amargo. Outra característica fisiológica desde a infância é a rejeição para alimentos novos e a habilidade para adquirir preferências alimentares baseadas nas consequências pós-ingestão de vários tipos de alimentos. Por outro lado, poucas preferências alimentares são inatas. A maioria é aprendida pelas experiências obtidas com a comida e a ingestão, e envolve condição associativa com o aspecto de ambiência alimentar infantil, especialmente no contexto social (BIRCH, 1999).

Em relação à oferta do pequi nos restaurantes/bares de Palmas, encontraram-se os seguintes dados: 65\% dos estabelecimentos ofertam pequi no seu cardápio, sendo que $64 \%$ disponibilizam o pequi misturado com galinha, arroz ou feijão. Outros restaurantes oferecem refeições variadas com o pequi, como: risoto com lâminas de pequi, filé de frango com espuma de pequi, ravióli de frango com pequi na manteiga de ervas, pequi com carne de sol, pequi ao molho, entre outros.

Por meio das respostas dos restaurantes, percebe-se a influência da cultura local na formatação do cardápio oferecido pelos estabelecimentos. A alimentação regional mostra-se como um elemento fundamental para atrair clientes tanto com relação à alimentação convencional, que tem por objetivo a nutrição do visitante, quanto pelo fato de oferecer produtos alimentares regionais como parte integrante do patrimônio cultural dos povos (FAGLIARI, 2005). Em ambas as maneiras de se atender o cliente, o setor de alimentação destaca-se graças à sua importância na geração de recursos para a comunidade e na prestação de serviços (MASCARENHAS, 2010).

A gastronomia, conforme Mascarenhas (2010), tem vínculo com a atividade turística tanto por meio da produção dos alimentos, uma vez que as paisagens são elementos significativos para o turismo, como também por meio da transformação do alimento em prato típico ou regional que será apresentado ao visitante. $\mathrm{O}$ consumo de um alimento visto sob essa ótica deve considerar o processo desde a aquisição da matéria-prima, o transporte e a estocagem, até a manipulação e transformação em alimentos, ou seja, o preparo e o serviço, pois a percepção do gosto representa uma experiência mista e unitária de sensações olfativas, gustativas e táteis percebidas durante a degustação. $\mathrm{O}$ turismo gastronômico é uma das formas de preservação do patrimônio imaterial à medida que se apropria da cultura, transformando-se em produtos para o consumo. Nesse sentido, a gastronomia é uma das manifestações que caracterizam o patrimônio cultural e que conforme Ávila (2009) pode ser utilizada pelo turismo como atrativo turístico. A gastronomia é um recurso de base territorial que pode ser transformada em produto.

Nos restaurantes a buffet, essa oferta ocorre da seguinte forma: $32 \%$ só ofertam o pequi na estação (de agosto a outubro) e com uma média de oito vezes por mês; $27 \%$ de uma a duas vezes por mês; $23 \%$ por cinco vezes ou mais; $14 \%$ por quatro vezes e $4 \%$ não souberam responder. Isso mostra que o pequi é ofertado com frequência, mesmo fora da sua estação. Os comerciantes afirmaram que é possível encontrar essa iguaria fora desse período, mas em pequena quantidade, e que também o congelam para a sua utilização ao longo do ano.

\section{Considerações finais}

O pequizeiro é uma árvore nativa, característica do cerrado brasileiro, especialmente nos estados de Goiás, Maranhão, Piauí, Ceará, Distrito Federal e Tocantins, sendo objeto desta pesquisa. Seu fruto, 
o pequi, atrai apreciadores curiosos, por ser um alimento que pode causar para algumas pessoas certa estranheza ou simplesmente o contentamento, auxiliando ainda na medicina caseira.

Entende-se com este trabalho que o consumo de pequi é um elemento de diferenciação de culturas. Sua identidade é bem definida pela oferta desse alimento na cadeia de restaurantes de Palmas, onde o pequi tem notoriedade nos cardápios e busca atender aos diversos paladares. Nesse sentido, destaca-se a importância do chefe de cozinha, que deve utilizar a criatividade para criar pratos que desmistifiquem a má fama do pequi.

Desse modo, o trabalho, que teve como objetivo analisar de que forma a gastronomia e a cultura estão interligadas, por meio do consumo do pequi na cidade de Palmas - TO, tanto por turistas quanto pelos moradores, foi positivo. Foi possível identificar que o fruto pequi mostra-se muito apreciado pela comunidade local da capital, sendo um tipo de alimentação bem aceito pela maioria de sua população.

Entretanto, para os turistas, o pequi não chega a ser um alimento totalmente bem aceito, pelas características inatas do fruto, que transmite a sensação de aversão quando experimentado pela primeira vez. Essa reação é justificada pelo sabor exótico do fruto, o qual tem cheiro forte e muitas vezes não agrada, principalmente quando os consumidores não têm o hábito cultural e promovem barreiras negativas de conhecimento de novos sabores.

Assim, Palmas se destaca pelo seu regionalismo presente no prato, com evidência para o pequi que é um alimento bem ofertado pela rede de restaurantes da cidade, sendo preparado de várias formas, agradando o consumidor final pela composição e variedades de combinações desse fruto. Dessa forma, a relação do pequi com cozinha resulta na combinação da cozinha regional, relacionando-se com a história, a geografia do lugar e com uma maior facilidade na busca pelos ingredientes - pequi - sendo mais sustentável econômica, ambiental e socialmente, devido à agilidade da rede de fornecedores locais para aquisição dos ingredientes básicos (MURTA; SOUZA; CARRIERI, 2010).

Por fim, percebe-se com este estudo que o pequi é um alimento bastante apreciado também pelos proprietários dos restaurantes, que incentivam a oferta de pratos à base de pequi várias vezes por mês e ainda fora do período de produção. Para isso, esses empreendedores sabiamente congelam o fruto e assim podem oferecê-los por mais vezes durante outras épocas do ano, o que valoriza o produto e faz dele um elemento de diferenciação e pertencimento da cultura, além de compor a oferta turística como um atrativo cultural, tornando a relação com o turista muito mais proveitosa e enriquecedora.

\section{Referências}

ADTUR. Revelando Tocantins: turismo consciente, futuro sustentável, v. 1. Palmas, TO: Governo do Estado do Tocantins, 2011.

ALVAREZ. M. La cocina como patrimônio (in)tangible. In: MARONESE, I. (Org.). Primeiras jornadas de patrimônio gastronômico. Buenos Aires: CPPHC-CABA, 2002.

ÁVILA, M. A. (Org.). Política e planejamento em cultura e turismo. Ilhéus: Editora da UESC, 2009.

BELUZZO. R. A valorização da cozinha regional. In: 1ํ․ CONGRESSO BRASILEIRO DE GASTRONOMIA E SEGURANÇA ALIMENTAR, Brasília - DF. Coletânea de palestras. Brasília, 2004. 
BIRCH, L. L. Os padrões de aceitação do alimento pelas crianças. Anais Nestlé, v. 57, p. 12-20, 1999. CARNEIRO, H. Comida e Sociedade: uma história da alimentação. Rio de Janeiro: Campus, 2003.

CASTELLI, G. Gestão Hoteleira. São Paulo: Saraiva, 2006.

DENCKER, A. F. M. Pesquisa em turismo: planejamento, métodos e técnicas. São Paulo: Futura, 1998.

DEUS, T. N. de. Extração e caracterização de óleo do pequi (Caryocar Brasiliensis Camb.) para o uso sustentável em formulações cosméticas óleo/água (o/a). 2008. 75 f. Dissertação (Mestrado em Ecologia e Produção Sustentável) - Universidade Católica de Goiás, Goiás, 2008.

DIAS, R. Turismo e patrimônio cultural: recursos que acompanham o crescimento das cidades. São Paulo: Saraiva, 2006.

DUTRA, V. C. Monitoramento de indicadores-chave do turismo sustentável em unidades de conservação: um estudo de caso no Parque Estadual do Jalapão - Tocantins. 2016. 296 f. Tese (Doutorado em Ciências) - Universidade de São Paulo, São Paulo, 2016.

FAGLIARI, G. S. Turismo e Alimentação: análises introdutórias. São Paulo: Rocca, 2005.

FRANCO, A. De caçador a gourmet: uma história da gastronomia. São Paulo, SP: Senac, 2001.

FREIXA, D.; CHAVES, G. Gastronomia no Brasil e no Mundo. Rio de Janeiro: Senac Nacional, 2012.

GÂNDARA, J. M. G.; GIMENES, M. H. S. G.; MASCARENHAS, R. G. Reflexões sobre o turismo gastronômico na perspectiva da sociedade dos sonhos. In: PANOSSO NETTO, A.; ANSARAH, M. G. (Org.). Segmentação do mercado turístico: estudos, produtos e perspectivas. Barueri, SP: Manole, 2009.

GARCIA, R. W. D.; CASTRO, I. R. R. A culinária como objeto de estudo e de intervenção no campo da Alimentação e Nutrição. Ciência e Saúde Coletiva, Rio de Janeiro, v. 16, n. 1, 2011. 92p.

GARCIA, R. W. D. Reflexos da Globalização na Cultura Alimentar: considerações sobre as mudanças na alimentação urbana. Revista de Nutrição, v. 16, n. 4, p. 483-492, 2003.

GIARD, L. Cozinhar. In: CERTEAU, M. de. A invenção do cotidiano: morar, cozinhar. Petrópolis, RJ: Vozes, 1996.

GIMENES, M. H. S. G. Viagens, sabores e cultura: reflexões sobre pratos típicos no contexto do turismo gastronômico. In: POSSAMAI, A. M. de P.; PECCINI, R. (Org.). Turismo, história e gastronomia: uma viagem pelos sabores. Caxias do Sul, RS: Educs, 2011.

. Cozinhando a tradição: festa, cultura, história e turismo no litoral paranaense. Curitiba, PR: Editora UFPR, 2013.

Instituto Brasileiro de Geografia e Estatística. Censo demográfico 2010: banco de dados Sidra. Disponivel em: 〈http://www.sidra.ibge.gov.br/cd/cd2010RgaAdAgsn.asp〉. Acesso em: 08 jun. 2015.

LAN, L. W.; WU, W. W.; LEE, Y. T. Promoting Food Tourism with Kansei Cuisine Design. Procedia Social and Behavioral Sciences, v. 40, p. 609-615, 2012.

LEAL, M. L. de M. S. A História da Gastronomia. Rio de Janeiro: Senac Nacional, 2007.

MACIEL, M. E.; MENASCHE, R. Alimentação e cultura, identidade e cidadania - você tem fome de quê? Democracia Viva. Especial Segurança Alimentar, v. 16, mai-jun, p. 3-7, Rio de Janeiro: 2003. 
MASCARENHAS, R. G. T. A diversidade gastronômica como atrativo turístico na região dos Campos Gerais do Paraná: um estudo de caso no município de Castro. 2009. Tese. (Doutorado em Geografia) - Universidade Federal do Paraná - UFPR. Curitiba, 2009.

MURTA, I. B. D.; SOUZA, M. M. P. de; CARRIERI, A. de P. Práticas Discursivas na Construção de uma Gastronomia Polifônica. RAM - Revista de Administração Mackenzie, v. 11, n. 1, São Paulo: 2010.

OLIVEIRA, D. L.; ROCHA, C. Alternativas sustentáveis para a merenda escolar com o uso de plantas do cerrado, promovendo educação ambiental. In: Revista Eletrônica Mestrado Educação Ambiental, v. 21, jul./dez, Porto Alegre, RS: 2008.

POULAIN, J. P. Sociologia da alimentação. Florianópolis: Editora UFSC, 2004.

RAMOS, M.; STEIN, L. M. Desenvolvimento do comportamento alimentar infantil. Jornal de Pediatria, V. 76, supl. 3, p. 229-237, 2000.

RAOSOFT. Simple size calculator. Disponível em: 〈http://www.raosoft.com/samplesize.html〉. Acesso em: 20 fev. 2015.

REINHARDT, J. C. 0 pão nosso de cada dia - a Padaria América e o pão das gerações curitibanas. Curitiba, 2002. Dissertação (Mestrado em História) - Setor de Ciências Humanas, Letras e Artes, Universidade Federal do Paraná, 2002.

RITCHIE, J. R. B.; TUNG, V. W. S.; RITCHIE, R. J. B. Tourism experience management research: emergence, evolution and future directions. International Journal of Contemporary Hospitality Management, $v$. 23, 4. ed., p. 19-38, 2011.

RODRIGUES, E. T. Frutos do Cerrado: a influência dos frutos do cerrado na diversificação da gastronomia. 2004. 92 f. Monografia. (Pós-graduação em Gastronomia e Segurança Alimentar) Universidade de Brasília, Brasília, DF: 2004.

SANTOS, B. R. et al. Pequizeiro (Caryocar Brasiliense Camb.): uma espécie promissora do cerrado brasileiro. Lavras, MG: Ed. UFLA, 2005.

SANTOS, C. R. A. Por uma história da alimentação. História: questões e debates, v. 14, n. 26/27, p. 154-171, jan./dez., Curitiba, PR: 1997.

SCHLUTER, R. G. Gastronomia e turismo. São Paulo: Aleph, 2003. 